\title{
Data report: amorphous silica content of sediment from Sites C0011 and C0012 in the Shikoku Basin on the NanTroSEIZE transect ${ }^{1}$
}

\author{
Glenn A. Spinelli ${ }^{2}$ and Ashley Hutton ${ }^{2}$
}

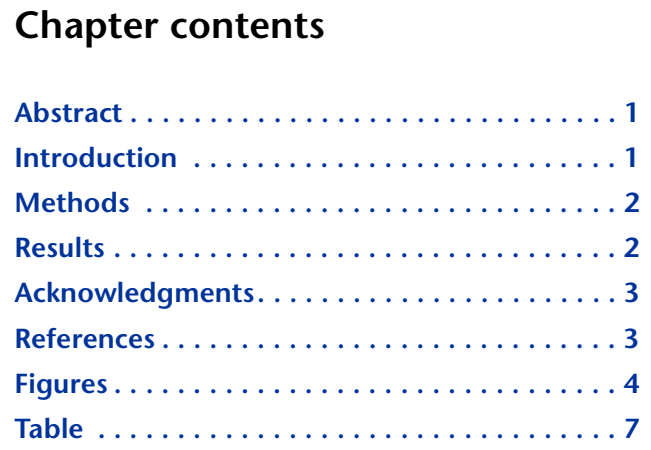

'Spinelli, G.A., and Hutton, A., 2013. Data report: amorphous silica content of sediment from Sites C0011 and C0012 in the Shikoku Basin on the NanTroSEIZE transect. In Saito, S., Underwood, M.B., Kubo, Y., and the Expedition 322 Scientists, Proc. IODP, 322: Tokyo (Integrated Ocean Drilling Program Management International, Inc.). doi:10.2204/iodp.proc.322.204.2013

${ }^{2}$ Earth and Environmental Science Department, New Mexico Institute of Mining and Technology, Socorro NM 87801, USA.

Correspondence author: spinelli@nmt.edu

\begin{abstract}
We determined the amorphous silica content of sediment from two sites in Shikoku Basin along the Nankai Trough Seismogenic Zone Experiment transect, offshore southern Japan. We examined hemipelagic mud from Sites C0011 and C0012 cored during Expeditions 322 and 333 of the Integrated Ocean Drilling Program. We determined amorphous silica content using an alkaline leaching technique. Amorphous silica content is $\leq 1.1 \mathrm{wt} \%$ in all samples. Amorphous silica content is higher in the shallow sediment (lithologic Subunit IA) than in the deeper sediment. At Site C0011, amorphous silica content decreases from $0.75-1.10 \mathrm{wt} \%$ in Subunit IA (above 252 meters below seafloor [mbsf]) to 0.13-0.59 $\mathrm{wt} \%$ in deeper lithologic units (below $252 \mathrm{mbsf}$ ). At Site C0012, four samples from Subunit IA contain 0.58-0.66 wt\% amorphous silica; samples from deeper lithologic units contain 0.13-0.40 wt $\%$ amorphous silica.
\end{abstract}

\section{Introduction}

Integrated Ocean Drilling Program (IODP) Expeditions 322 and 333 are part of the Nankai Trough Seismogenic Zone Experiment (NanTroSEIZE). One goal of that project is to determine how geologic differences affect mechanical properties, permeability, fluid flow, pore pressure, shear strength, and earthquake rupture processes within the subduction zone (Tobin and Kinoshita, 2006). Material on the plate approaching the Nankai Trough was sampled during Expeditions 322 and 333 in order to quantify the inputs to the subduction system.

We focus on amorphous silica within the sedimentary section on the incoming plate at Sites C0011 and C0012. Amorphous silica may cement grain contacts, strengthening the sediment and influencing deformation in the NanTroSEIZE transect (Spinelli et al., 2007). Portions of the sedimentary section approaching the Nankai Trough subduction zone at Ocean Drilling Program (ODP) Sites 1173 and 1177 have anomalous porosity, seismic velocity, and rigidity caused by small amounts $(\sim 1 \mathrm{wt} \%)$ of amorphous silica cement (Spinelli et al., 2007; White et al., 2011). These anomalies are consistent with experimental work demonstrating that even a very small volume of grain-coating cement can greatly increase sediment strength (e.g., Clough et al., 1981; Karig, 1993). Amorphous silica is rare in Shikoku Basin sediment; it is $1 \%$ of 
the shallow sediment at Sites 1173 and 1177 and Deep Sea Drilling Project (DSDP) Sites 297, 442, 443, and 444 (Spinelli et al., 2007; White et al., 2011). Although biogenic silica (i.e., opal-A) is usually the most common form of amorphous silica in seafloor sediment (Barron and Whitman, 1981), the dominant constituent of amorphous silica in Shikoku Basin sediment is volcanic glass (White et al., 2011).

The strength of sediment entering a subduction zone controls the nature and distribution of sediment deformation (Karig and Morgan, 1994). Determining the amorphous silica content at Sites C0011 and C0012 helps quantify the distribution and abundance of silica cement along the Nankai Trough subduction zone system.

\section{Methods}

When placed in an alkaline solution, amorphous silica (e.g., glass) dissolves more quickly than structured silicates (e.g., clay minerals). This difference in dissolution rates allows us to use the amount of dissolved silica leached from a sediment sample over time to determine the original amount of amorphous silica in the sample.

The amorphous silica contents of 36 samples were measured using an alkaline leaching method modified from DeMaster (1981). Freeze-dried, crushed sediment samples were dissolved in a $1 \%$ sodium carbonate solution at $85^{\circ} \mathrm{C}$. We used a leachate with $\mathrm{pH} 11.4$ in order to minimize digestion of clay minerals (Schlüter and Rickert, 1998). Aliquots of the leachate were collected $15,30,60,90,120,200$, and $300 \mathrm{~min}$ after digestion began. The silica concentration in each aliquot was determined by spectrophotometry (e.g., Grasshoff et al., 1983).

The concentration of dissolved silica in the leachate increases over time. A rapid initial increase occurs, largely caused by the dissolution of amorphous silicates, followed by a gradual increase in dissolved silica concentration resulting from the slow dissolution of structured silicates (Fig. F1). The dissolution rate of the structured silicates is assumed to be constant throughout the entire dissolution process (DeMaster, 1981). We fit a line to the late, low-slope portion of the concentration curve. Projecting this line to the time when digestion began accounts for the contribution of structured silicate dissolution to the dissolved silica concentration during early time, when the signal is dominated by amorphous silicate dissolution (Fig. F1). The $y$-intercept of this line indicates the total contribution from amorphous silicate to the dissolved silica in the leachate. Error estimates for the amorphous silica content are determined from the $95 \%$ confidence interval on this $y$-intercept value. Commonly, it takes longer for samples with more amorphous silica to reach the steadily increasing dissolved silica concentration trend (i.e., longer for all amorphous silica to dissolve), relative to samples with less amorphous silica. Therefore, for samples with more amorphous silica, the line fit to the low-slope portion of the concentration curve must be projected farther from the data used to define the line to the $y$-intercept. As a result, there is more uncertainty in the $y$-intercept value (and the amorphous silica content) of samples with more amorphous silica. For replicates of samples from the Middle America margin (Spinelli and Underwood, 2004 ) the maximum error is $12 \%$. In addition, some uncertainty in calculating the weight percent of amorphous silica in the bulk samples derives from potential variability in the molecular weight of amorphous silica $\left(\mathrm{SiO}_{2} \cdot n \mathrm{H}_{2} \mathrm{O}\right)$. We assume the amorphous silica is $11 \%$ water by weight, which is consistent with hydrated glass shards in Shikoku Basin sediment (White et al., 2011) and global estimates for opal (Keene, 1976).

This technique uses physiochemical differences between amorphous and structured silicates to quantify the amorphous silica content of sediment samples. With this technique, we cannot discern the type of amorphous silica present in the sediment (e.g., volcanic glass, biogenic opal, etc.). All sediment samples analyzed in this study are hemipelagic mud (Underwood et al., 2010; Expedition 333 Scientists, 2012). Previous electron microprobe image analyses of similar clay-dominated Shikoku Basin sediment found disseminated volcanic glass shards more common than biogenic opal (White et al., 2011).

\section{Results}

The amorphous silica content of sediment from Sites C0011 and C0012 are summarized in Figures F2 and F3 and Table T1. The amorphous silica content in all samples examined is $\leq 1.1 \mathrm{wt} \%$. The amorphous silica content is higher in the shallow sediment than in the deeper sediment. At Site C0011, in lithologic Subunit IA, the sediment ranges from 0.75 to 1.11 wt $\%$ amorphous silica and averages 0.93 wt $\%$ amorphous silica. The Subunit IA/IB boundary at 252 meters below seafloor (mbsf) is defined at a sharp gradient in volcanic ash alteration; fresh volcanic glass is above the boundary and altered ash layers with little remaining glass are below the boundary (Expedition 333 Scientists, 2012). The measured amorphous silica content decreases sharply across the Subunit IA/ IB boundary (Fig. F2). Below the boundary, sediment ranges from 0.13 to $0.59 \mathrm{wt} \%$ amorphous silica and averages $0.36 \mathrm{wt} \%$ amorphous silica (Fig. F2). 
Similar to Site C0011, the amorphous silica content at Site C0012 is higher in the shallow sediment than in the deeper sediment. The four samples examined in Subunit IA average $0.63 \mathrm{wt} \%$ amorphous silica (standard deviation $=0.4 \mathrm{wt} \%)$ (Fig. F3). Samples below the Subunit IA/IB boundary average $0.26 \mathrm{wt} \%$ amorphous silica (standard deviation $=0.08 \mathrm{wt} \%$ ) (Fig. F3). The Subunit IA/IB boundary at $72 \mathrm{mbsf}$ is a transition below which ash layers are scarce and volcanic glass shards are more altered (Expedition 333 Scientists, 2012).

\section{Acknowledgments}

This research used samples provided by the Integrated Ocean Drilling Program (IODP). We thank the participants and technical staff of IODP Expeditions 322 and 333. Funding was provided by the Consortium for Ocean Leadership through the U.S. Science Support Program. We thank M. Underwood and an anonymous reviewer for thoughtful reviews of the manuscript.

\section{References}

Barron, E.J., and Whitman, J.M., 1981. Ocean sediments in space and time. In Emiliani, C. (Ed.), The Oceanic Lithosphere: New York (Wiley), 689-731.

Clough, G.W., Rad, N.S., Backus, R.C., and Sitar, N., 1981. Cemented sands under static loading. J. Geotech. Eng., 107(6):799-817.

DeMaster, D.J., 1981. The supply and accumulation of silica in the marine environment. Geochim. Cosmochim. Acta, 45(10):1715-1732. doi:10.1016/ 0016-7037(81)90006-5

Expedition 333 Scientists, 2012. Expedition 333 summary. In Henry, P., Kanamatsu, T., Moe, K., and the Expedition 333 Scientists, Proc. IODP, 333: Tokyo (Integrated Ocean Drilling Program Management International, Inc.). doi:10.2204/iodp.proc.333.101.2012

Grasshoff, K., Ehrhardt, M., and Kemling, K. (Eds.), 1983. Methods of Seawater Analysis: Weinheim, Germany (Verlag Chemie Int.).
Karig, D.E., 1993. Reconsolidation tests and sonic velocity measurements of clay-rich sediments from the Nankai Trough. In Hill, I.A., Taira, A., Firth, J.V., et al., Proc. ODP, Sci. Results, 131: College Station, TX (Ocean Drilling Program), 247-260. doi:10.2973/odp.proc.sr.131.127.1993

Karig, D.E., and Morgan, J.K., 1994. Tectonic deformation: stress paths and strain histories. In Maltman, A. (Ed.), The Geological Deformation of Sediments: London (Chapman and Hall), 167-204.

Keene, J.B., 1976. The distribution, mineralogy, and petrography of biogenic and authigenic silica from the Pacific Basin [Ph.D. dissert.]. Univ. California, San Diego.

Schlüter, M., and Rickert, D., 1998. Effect of $\mathrm{pH}$ on the measurement of biogenic silica. Mar. Chem., 63(1-2):8192. doi:10.1016/S0304-4203(98)00052-8

Spinelli, G.A., Mozley, P.S., Tobin, H.J., Underwood, M.B., Hoffman, N.W., and Bellew, G.M., 2007. Diagenesis, sediment strength, and pore collapse in sediment approaching the Nankai Trough subduction zone. Geol. Soc. Am. Bull., 119(3-4):377-390. doi:10.1130/B25920.1

Spinelli, G.A., and Underwood, M.B., 2004. Character of sediments entering the Costa Rica subduction zone: implications for partitioning of water along the plate interface. Isl. Arc, 13(3):432-451. doi:10.1111/j.14401738.2004.00436.x

Tobin, H.J., and Kinoshita, M., 2006. NanTroSEIZE: the IODP Nankai Trough Seismogenic Zone Experiment. Sci. Drill., 2:23-27. doi:10.2204/iodp.sd.2.06.2006

Underwood, M.B., Saito, S., Kubo, Y., and the Expedition 322 Scientists, 2010. Expedition 322 summary. In Saito, S., Underwood, M.B., Kubo, Y., and the Expedition 322 Scientists, Proc. IODP, 322: Tokyo (Integrated Ocean Drilling Program Management International, Inc.). doi:10.2204/iodp.proc.322.101.2010

White, R.J., Spinelli, G.A., Mozley, P.S., and Dunbar, N.W., 2011. Importance of volcanic glass alteration to sediment stabilization: offshore Japan. Sedimentology, 58(5):1138-1154. doi:10.1111/j.13653091.2010.01198.x

Initial receipt: 30 May 2012

Acceptance: 12 November 2012

Publication: 22 January 2013

MS 322-204 
Figure F1. Plots of examples of data used to determine amorphous silica content, Site C0011. The rapid increase in silica concentration in the leachate within the first $\sim 30 \mathrm{~min}$ results primarily from amorphous silica dissolution (open circles). Structured silicates dissolve slowly and continue to contribute silica to the leachate after all amorphous silica has been dissolved (solid circles). The contribution of silica to the leachate from amorphous material alone is determined by projecting a line fit to the late data (dashed line) to time $=0$.

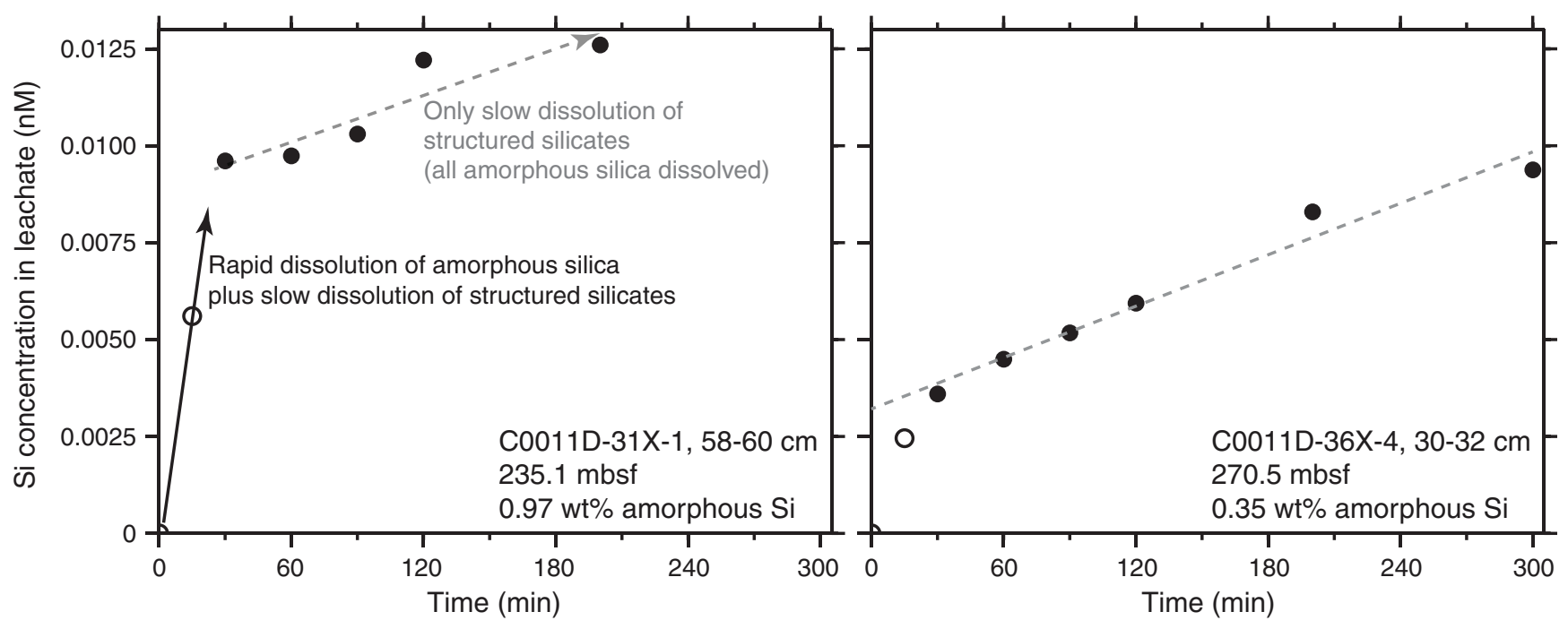


Figure F2. Plot of amorphous silica content of bulk sediment samples, Site C0011. Error bars indicate 95\% confidence intervals. Horizontal dashed lines are lithologic unit and subunit boundaries from Expedition 333 Scientists (2012). The Subunit IA/IB boundary is defined at a change in the degree of volcanic ash alteration, with greater alteration below the boundary (Expedition 333 Scientists, 2012).

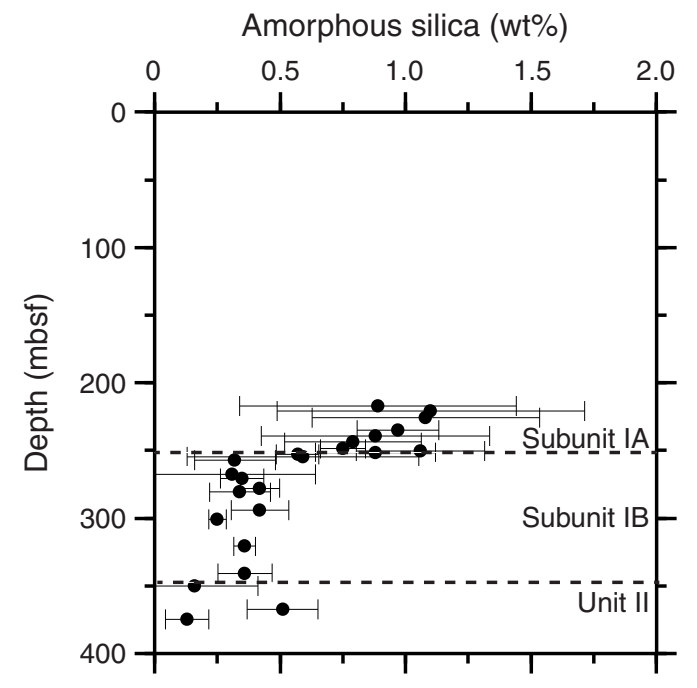


Figure F3. Plot of amorphous silica content of bulk sediment samples, Site C0012. Error bars indicate 95\% confidence intervals. Horizontal dashed lines are lithologic unit and subunit boundaries from Expedition 333 Scientists (2012) and Underwood et al. (2010). Below the Subunit IA/IB boundary, ash layers become scarce and volcanic glass is more altered (Expedition 333 Scientists, 2012).

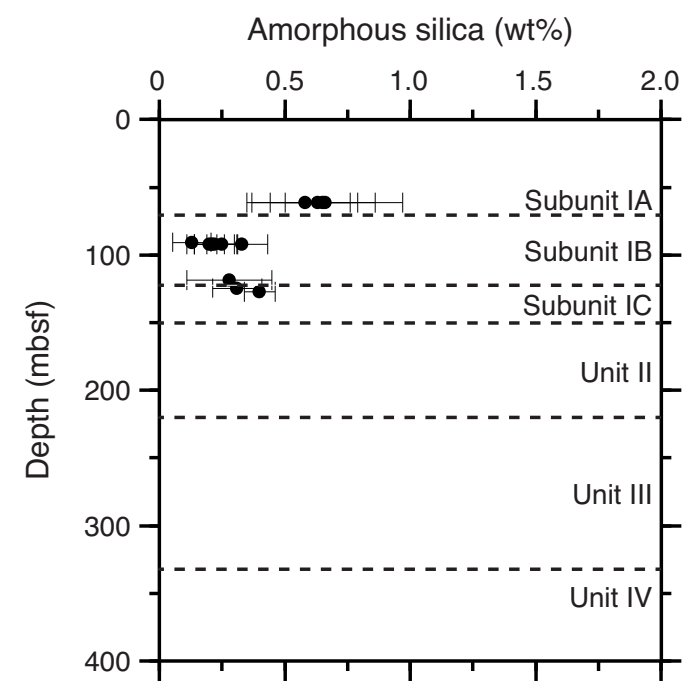


Table T1. Amorphous silica content of bulk sediment samples, Expeditions 322 and 333.

\begin{tabular}{|c|c|c|c|}
\hline Hole, core, section & $\begin{array}{l}\text { Depth } \\
\text { (mbsf) }\end{array}$ & $\begin{array}{l}\text { Amorphous } \\
\text { silica (wt\%) }\end{array}$ & \pm \\
\hline 333-C0011D-28X-2 & 217.27 & 0.89 & 0.55 \\
\hline 333-C0011D-29X-1 & 220.81 & 1.10 & 0.61 \\
\hline 333-C0011D-30X-1 & 225.75 & 1.08 & 0.45 \\
\hline 333-C0011D-31X-1 & 235.08 & 0.97 & 0.16 \\
\hline 333-C0011D-31X-5 & 239.41 & 0.88 & 0.46 \\
\hline 333-C0011D-32X-1 & 243.89 & 0.79 & 0.27 \\
\hline 333-C0011D-33X-2 & 248.74 & 0.75 & 0.09 \\
\hline 333-C0011D-33X-4 & 250.42 & 1.06 & 0.26 \\
\hline 333-C0011D-33X-5 & 251.30 & 0.88 & 0.24 \\
\hline 333-C0011D-34X-1 & 252.82 & 0.57 & 0.08 \\
\hline 333-C0011D-34X-3 & 254.47 & 0.59 & 0.46 \\
\hline 333-C0011D-34X-5 & 257.27 & 0.32 & 0.16 \\
\hline 333-C0011D-36X-2 & 267.51 & 0.31 & 0.33 \\
\hline 333-C0011D-36X-4 & 270.53 & 0.35 & 0.09 \\
\hline 333-C0011D-37X-2 & 277.85 & 0.42 & 0.08 \\
\hline 333-C0011D-37X-5 & 280.74 & 0.34 & 0.12 \\
\hline 333-C0011D-39X-2 & 294.09 & 0.42 & 0.12 \\
\hline 333-C0011D-39X-8 & 300.83 & 0.25 & 0.04 \\
\hline 333-C0011D-42X-1 & 320.84 & 0.36 & 0.04 \\
\hline 322-C0011B-1R-1 & 340.63 & 0.36 & 0.11 \\
\hline 322-C0011B-2R-1 & 350.04 & 0.16 & 0.25 \\
\hline 322-C0011B-4R-4 & 367.39 & 0.51 & 0.14 \\
\hline 322-C0011B-5R-1 & 374.72 & 0.13 & 0.09 \\
\hline $333-\mathrm{C} 0012 \mathrm{C}-8 \mathrm{H}-1$ & 61.20 & 0.65 & 0.21 \\
\hline 333-C0012C-8H-1 & 61.21 & 0.63 & 0.13 \\
\hline $333-\mathrm{C} 0012 \mathrm{C}-8 \mathrm{H}-1$ & 61.27 & 0.58 & 0.21 \\
\hline $333-\mathrm{C} 0012 \mathrm{C}-8 \mathrm{H}-1$ & 61.28 & 0.66 & 0.31 \\
\hline 322-C0012A-5R-3 & 90.68 & 0.13 & 0.08 \\
\hline 322-C0012A-5R-4 & 92.01 & 0.21 & 0.10 \\
\hline 333-C0012C-11H-7 & 92.20 & 0.20 & 0.06 \\
\hline $333-\mathrm{C} 0012 \mathrm{C}-11 \mathrm{H}-7$ & 92.21 & 0.22 & 0.08 \\
\hline $333-\mathrm{C} 0012 \mathrm{C}-11 \mathrm{H}-7$ & 92.25 & 0.25 & 0.06 \\
\hline 333-C0012-11H-7 & 92.26 & 0.33 & 0.10 \\
\hline 322-C0012A-8R-7 & 118.46 & 0.28 & 0.17 \\
\hline 322-C0012A-9R-5 & 124.56 & 0.31 & 0.10 \\
\hline 322-C0012A-9R-7 & 127.34 & 0.40 & 0.06 \\
\hline
\end{tabular}

Adding or subtracting the \pm values from the reported amorphous silica values yields the upper and lower limits of the $95 \%$ confidence interval. 